\title{
USE OF WASTE GLASS IN IMPROVING SUBGRADE SOIL PROPERTIES
}

\author{
Mwajuma Ibrahim Lingwanda ${ }^{1}$ \\ ${ }^{1}$ Lecturer, Department of Built Environment Engineering, Mbeya University of Science and Technology, Mbeya, \\ Tanzania
}

\begin{abstract}
Pavement design standard in Tanzania require all subgrades to have a minimum California Bearing Ratio (CBR) value of $15 \%$ along with a Plasticity Index (PI) of not more than 25\%. If these conditions are not fulfilled, improvement is mandatory. There are many cases where the natural subgrade fails the criteria. On the other hand, waste materials such as glass may be available locally or at a nearby distance. In many areas of the country, resources may not be available for recycling the glass. This study proposes improvement of a clay soil subgrade using crushed glass whereby a $10 \%$ by weight of the natural soil has resulted to an increase in CBR by $300 \%$ and a decrease in PI by $46 \%$ thus achieving the required quality as stipulated in the relevant standard. Environmental studies are recommended to forecast the possible effect of using crushed glass in subgrade improvement and propose appropriate counter measures.
\end{abstract}

Keywords: - Subgrade improvement, waste glass, Tanzania pavement design standard, soil stabilization using waste materials.

\section{INTRODUCTION}

In Tanzania, pavement design is guided by the Ministry of Works Pavement and Materials Design Manual [1]. The manual gives directives in material selection, treatment, characterization and application, among other road design aspects. Minimum requirements of each pavement layer under certain traffic and weather conditions are well elaborated. When it comes to subgrade strength, the catalogue requires all subgrades to have a minimum California Bearing Ratio (CBR) value of $15 \%$ either naturally or by provision of an improved layer whenever the strength is lower. Furthermore, the subgrade material is required to have a Plasticity Index (PI) value not exceeding $25 \%$. In case an improved layer is suggested, the material for such use should be non-expansive, non-dispersive and free from deleterious matter.

In practice, there are many cases where existing subgrades do not pass the stipulated minimum requirements hence improvement by modifying properties or use of borrow material becomes necessary. Currently the most commonly used materials for modifying the existing properties are lime and cement which can be expensive and not available locally. Recently, researchers have started to pursue the application of seemingly non-conventional materials including industrial and agricultural wastes. Studies by Khan et al. [2] and Appiah et al. [3] for utilization of plastic waste, Salamatpoor and Salamatpoor [4] and Yin and Yu [5] on the use of waste glass, Basha et al. [6] and Roy [7] for application of rice husk ashes as well as Edil et al. [8] and Zumrawi [9] for application of fly ash, are well cited among many others. Recently, Lingwanda and Mnkeni [10] have shown that use of quarry dust can improve properties of a black cotton subgrade to acceptable quality. The use of waste materials has a twofold advantage; first is the utilisation of the waste material which could otherwise end up in landfills or destroy the environment and secondly there is a chance of reducing the overall road construction cost.

The suitability of a proposed subgrade stabilizing material depends on many factors including nature of the original material, amount of the stabilizer, environmental factors, traffic factors, type of pavement layers to be placed on the subgrade and the characteristics of the soil that are to be achieved after stabilization. It is obvious that these factors will vary from country to country, place to place and even project to project. It is therefore necessary to study the suitability of applying waste glass for improvement of natural properties of subgrade in rather specific conditions. In this study, the aim is to modify characteristics of a low strength, high plasticity subgrade soil so as to achieve the minimum criteria specified for road pavements in Tanzania as per MoW [1] standards.

\section{METHODOLOGY}

A soil sample was collected from a road section in Mbeya region which is known to have a clayey subgrade. The soil was brought to a laboratory for determination of its natural properties. Meanwhile waste glass was collected from a nearby waste disposal area and prepared. The preparation involved cleaning of the waste glass to remove debris and then crushing the glass after it dried. Crushing was done in the laboratory by using the Los Angeles Abrasion machine which is normally used to determine aggregate quality. The 
machine consists of a rotating drum with steel balls in it which facilitate the abrasion of aggregate samples when placed in the drum and rotated. The machine was rotated until the glass was crushed in a manner that a mixture of fine to gravel sized particles were visibly seen. The idea was to have a non-uniform gradation covering a wider range of particle sizes so as to achieve better results in compaction as compared to uniform sized particles. The gradation of the crushed glass was then determined and plotted. The prepared crushed glass was mixed with the natural soil starting with $2 \%$ by weight of soil with increments of $2 \%$ crushed glass until the minimum requirements of an improved subgrade was achieved. At each percentage of glass content, Atterberg limits, compaction characteristics and CBR were determined.

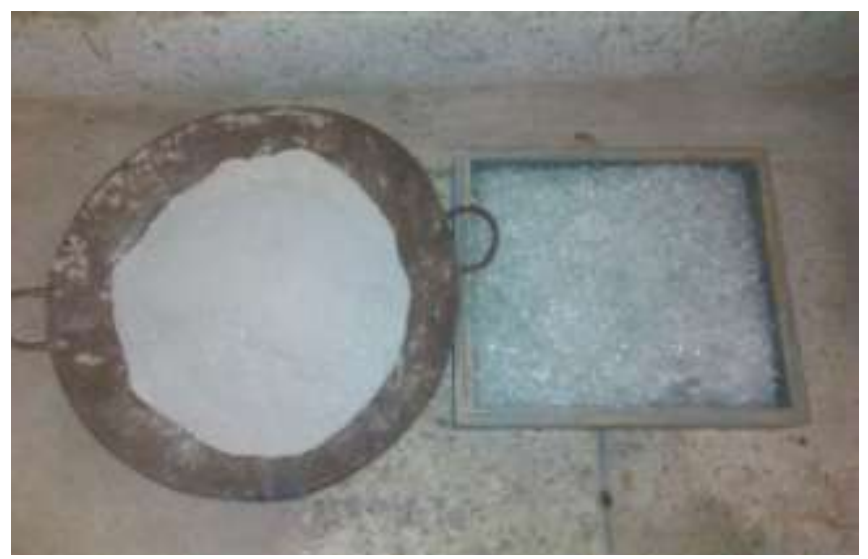

Fig -1: Crushed waste glass

\section{LABORATORY TEST RESULTS}

Wet sieving of the natural soil was conducted according to CML test no. 1.7, Atterberg limits according to tests no. 1.2, $1.3,1.4$, modified compaction test was according to test no. 1.9 whereas CBR test was performed with reference to test no. 1.11 of MoW [11]. The amount of gravel in the natural soil sample was determined to be $0.5 \%$, sand $8.7 \%$ and fine content was $90.8 \%$. Sieve analysis results for the crushed glass sample indicated that the amount of gravel was $23.6 \%$, sand was $36.4 \%$ and fines was $40.0 \%$. Atterberg limits test resulted to a Liquid Limit (LL) of 51, Plastic Limit (PL) of $25 \%$ and Plasticity Index (PI) of $26 \%$ for the natural soil. Linear shrinkage (LS) value for the natural soil was determined to be 8.6. According to AASHTO soil classification system, this soil is an A-7-6 clayey soil.

The natural water content of the soil was determined to be $3.7 \%$. Compaction test on the natural material indicated that a maximum dry density of $1425 \mathrm{~kg} / \mathrm{m}^{3}$ is achieved at an optimum water content of $21.5 \%$. After determination of compaction characteristics, CBR samples were prepared and soaked for 96 hours. After performing the three point CBR test, the CBR value for the natural soil was determined to be 4\%. Looking back at the MoW manual [1], where improved subgrade requirements of minimum CBR $15 \%$ and maximum PI 25\% are specified, you will notice that the natural soil which was determined to have a CBR of $4 \%$ and a PI of $26 \%$ needs improvement in strength more than plasticity characteristics. It was therefore decided to add a $2 \%$ of crushed glass by weight of natural soil at increments of $2 \%$ until the minimum CBR requirement is achieved and check the corresponding PI.

Starting with a $2 \%$ crushed glass, mixtures were prepared for natural soil - crushed glass and the following tests were performed to each mix; Atterberg limits, compaction and CBR. On reaching a $10 \%$ glass content, the minimum strength was achieved as the CBR was determined to be $16 \%$. At this point the gradation of the mix was also determined as indicated in Figure 2.

The variation of Atterberg limits with percentage crushed glass is plotted in Figure 3 where by a general decrease of PI is observed with increase in crushed glass percentage. At $10 \%$ crushed glass, a $46 \%$ decrease in PI was achieved. A significant decrease in shrinkage characteristics was also observed from $8.6 \%$ for the natural soil to $4 \%$ at $10 \%$ crushed glass. The maximum dry density was increased from $1425 \mathrm{~kg} / \mathrm{m}^{3}$ for the natural soil to $1650 \mathrm{~kg} / \mathrm{m}^{3}$ at $10 \%$ crushed glass content. This is an increment of about $16 \%$. The optimum moisture content varied from $21.5 \%$ for the original soil to $15.5 \%$ at $10 \%$ crushed glass which is a decrease of about $28 \%$. Figures 4,5 and 6 indicate the variation of compaction characteristics with variation in parentage crushed glass. The variation of CBR values with percentage crushed glass content is presented in Figure 7 where the CBR value increased from $4 \%$ to $16 \%$, equivalent to a $300 \%$ increase.

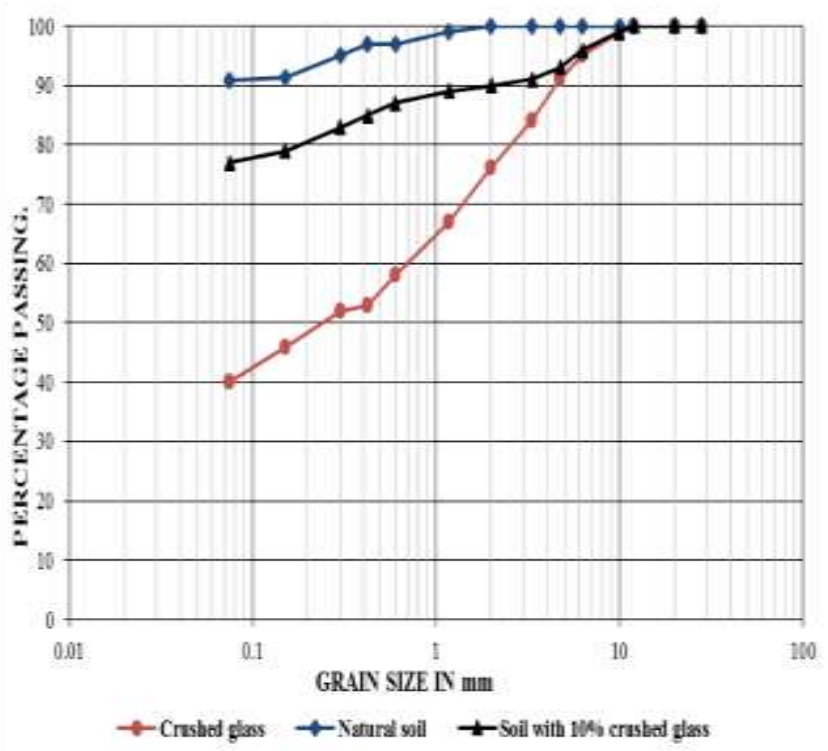

Fig -2: Gradation of soil, crushed glass and a mixture of the two 


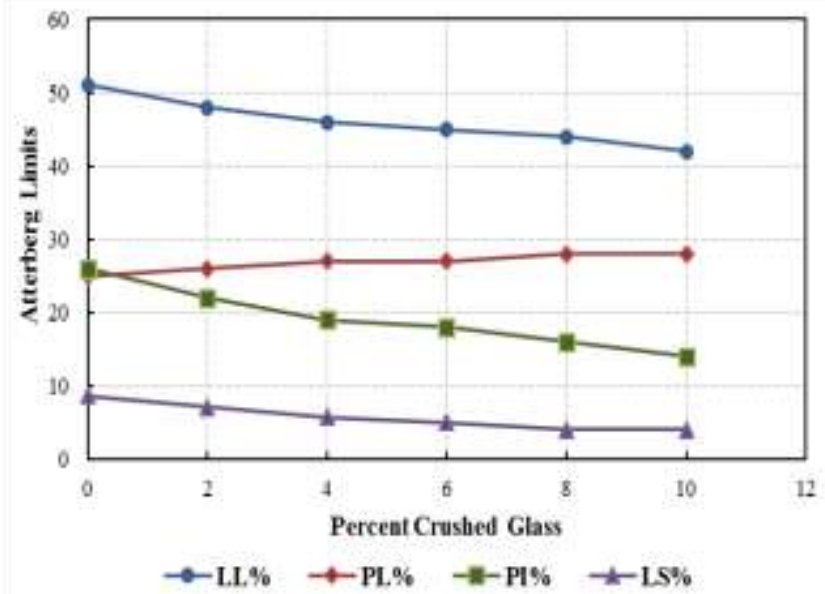

Fig -3: Variation of Atterberg limits with crushed glass content

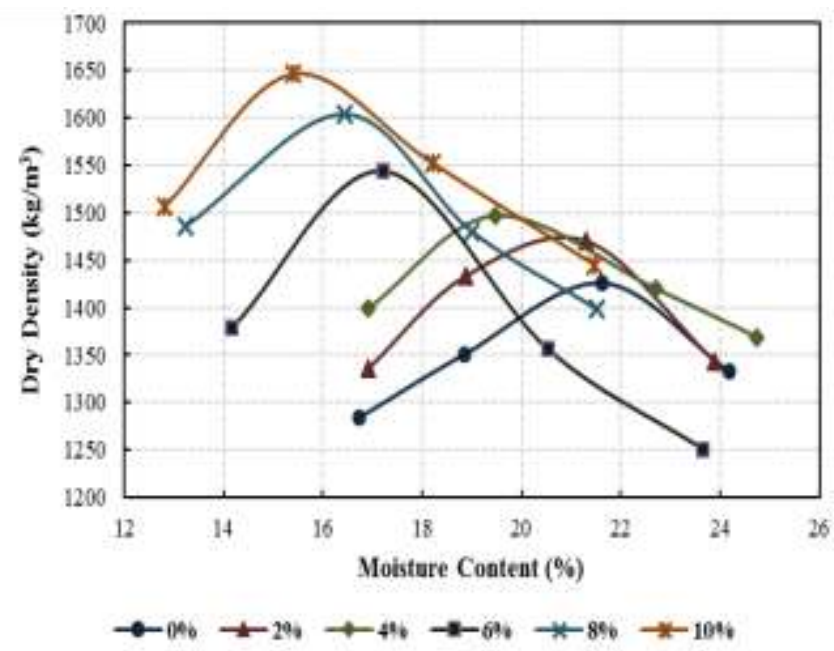

Fig -4: Compaction parameters at different crushed glass percentages

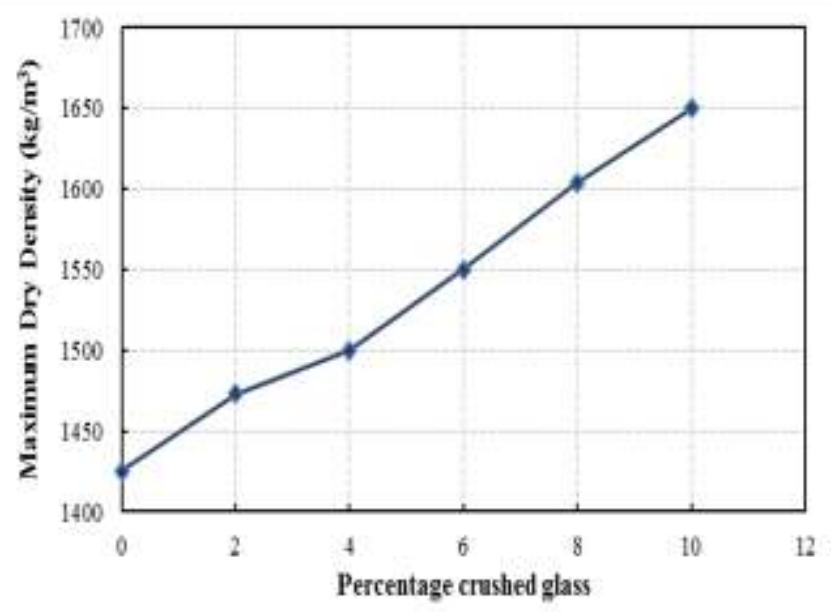

Fig -5: Variation of maximum dry density with percentage crushed glass

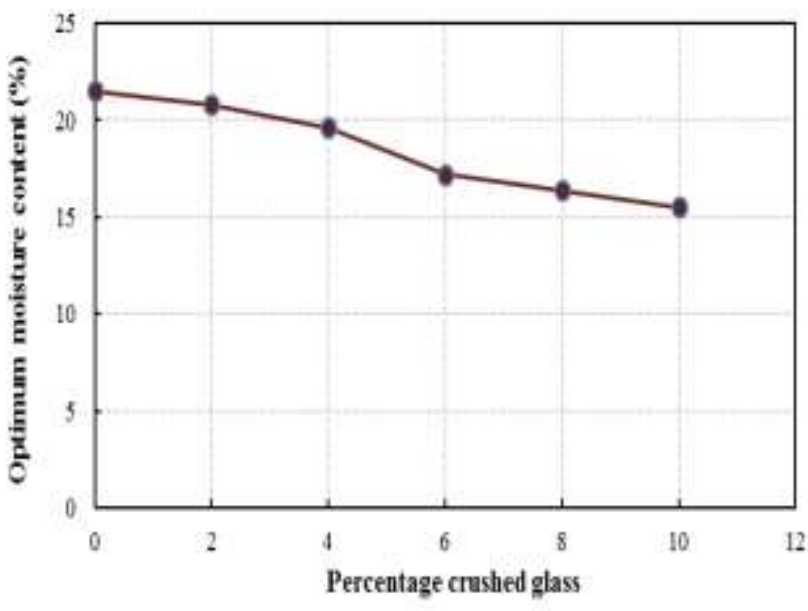

Fig -6: Variation of optimum moisture content with percentage crushed glass

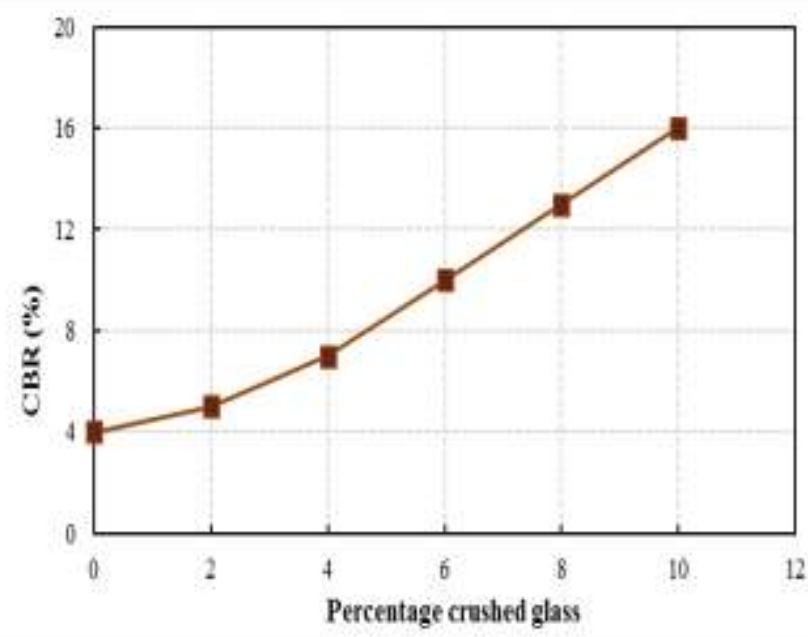

Fig -7: Variation of CBR values with percentage crushed glass

\section{DISCUSSION OF RESULTS}

\subsection{Percentage of Crushed Glass for the Required Improvement}

The natural soil in the present study was classified as anA 7 - 6 material according to AASHTO and it can be described as a poor subgrade. Moreover, according to Tanzania standards, such subgrade should be improved before application of other layers. In a similar study, Salamatpoor and Salamatpoor [4] found that $10 \%$ of crushed glass could significantly improve shear strength of sand soil. Two major differences as compared to the current study are that their natural material was non plastic and secondly the stabilization was enhanced with cement. In a study performed by $\mathrm{Yin}$ and $\mathrm{Yu}$ [5], the soil characteristic was somehow similar to this study especially in terms of plasticity. The major difference is that their stabilization involved cement and glass fiber. Moreover, the percentage of cement used was significantly greater than that of glass fiber. 
More relevant to this study is a study by Singh and Sadhwani [12] where a black cotton soil had both CBR and PI values similar to this study. However in their methodology, two separate considerations were pursued. One using fine crushed glass and the other using course grained crushed glass. Although they used up to $20 \%$ of crushed glass in their mixes, the improvement gained was significantly lower than what was achieved in this study in terms of reduced plasticity and increased strength. Their low strength improvement could be attributed to the gradation of the crushed glass being uniformly fine or course as opposed to what was done in the present study.

A $10 \%$ addition of crushed glass proposed in this study fulfils the aim of using waste material without industrial products such as cement which are generally more costly. In a developing country like Tanzania it would be more appropriate to use waste glass for subgrade stabilization rather than recycling the waste glass since the latter needs more expensive resources including high temperatures in a furnace. In addition, such costs as transportation to the recycling industry which could be far from where the waste is available should be accounted for. The major concern for application of this research results would be environmental impacts of using crushed glass and probably cost comparison with other available soil improvement alternatives.

\subsection{Effect of Crushed Glass on Soil Plasticity}

A $46 \%$ decrease in subgrade PI was achieved in this study by adding $10 \%$ crushed glass. Singh and Sadhwani [12] achieved a $24 \%$ decrease by adding $10 \%$ of fine glass to black cotton soil. The difference between these results signifies the importance of studying the suitability of crushed glass for improving different types of soils. Subgrades of high plasticity tend to have low strength [13] [14] even when un-soaked CBR samples are used [15]. This is due to a higher optimum moisture content and a lower maximum dry density of such soils when compacted. Rahim [16] showed that PI along with other soil indexes can affect the resilient modulus of subgrade which is an important parameter in mechanistic pavement design. Therefore, the PI is an important parameter in subgrade characterization hence the ability of crushed glass to significantly reduce it is a major benefit. Currently there is no literature evidence on the effect of too low plasticity of subgrade material and it could be worthy studying for the purpose of controlling the characteristics of the improved layer. It can be observed from this study that a further increase in crushed glass percentage would further reduce the PI.

\subsection{Effect of Crushed Glass on Soil Strength}

In this study, a $300 \%$ increase in soil strength in terms of CBR was achieved. This is due to a decrease in soil plasticity as well as increased maximum dry density with decreased moisture content. Singh and Sadhwani [12] were able to achieve a $40 \%$ increment in CBR after adding $10 \%$ of fine crushed glass but a better $111 \%$ increase on using courser glass at $20 \%$. Their less percentage increase in strength could be due to the nature of the virgin soil as well as the fact that they used uniformly graded crushed glass categorized separately as fine and course. The major drawback in the methodology of the current study is the fact that the gradation of the crushed glass was not controlled during crushing. It was just decided to have a non-uniform gradation of the crushed glass with a possibility of a well graded envelope from gravel to silt size. In future, the gradation should be controlled to a specified envelope based on the characteristics of the virgin soil requiring improvement.

\section{CONCLUSION}

Characterization of the natural soil found it unsuitable for pavement subgrade without some form of improvement. The proposed improvement is to mix the soil with $10 \%$ crushed glass by weight which could potentially improve the subgrade by lowering its PI from $26 \%$ to $14 \%$, lower its linear shrinkage from $8.6 \%$ to $4 \%$, increase the maximum dry density from $1425 \mathrm{~kg} / \mathrm{m}^{3}$ to $1650 \mathrm{~kg} / \mathrm{m}^{3}$, decrease the optimum moisture content from $22 \%$ to $16 \%$ and most importantly increase the soil strength from a CBR value of $4 \%$ to $16 \%$. The achieved improvements conform to minimum subgrade requirements as per MoW [1] specifications.

It is recommended for future studies to control the gradation of the crushed glass as it appears to influence final improvement results. A study is also recommended to determine the influence of too low subgrade plasticity for its performance and durability. This is because high percentages of crushed glass will cause a further decrease in plasticity of the improved soil. Short and long term environmental impacts of using crushed glass for road construction should be of concern hence recommended to be studied.

\section{ACKNOWLEDGEMENT}

The author acknowledges the contribution of Mr Perfect Kway who helped with samples and laboratory work

\section{REFERENCES}

[1] Ministry of Works Tanzania (MoW), (1999), Pavement and materials design manual, Allkopi AS, Oslo, Norway

[2] Khan, I.M., Kabir, S., Alhussain, M.A. and Almansoor, F.F., (2016). Asphalt design using recycled plastic and crumb-rubber waste for sustainable pavement construction. Procedia Engineering, 145, pp.1557-1564

[3] Appiah, J.K., Berko-Boateng, V.N. and Tagbor, T.A., (2017), Use of waste plastic materials for road construction in Ghana. Case Studies in Construction Materials, 6, pp.1-7. 
[4] Salamatpoor, S. and Salamatpoor, S., (2017), Evaluation of adding crushed glass to different combinations of cement-stabilized sand. International Journal of Geo-Engineering, 8(1)

[5] Yin, Y. and Yu, X.J., (2009), Research on applying glass fiber cement soil to strengthen soft soil subgrade. In Recent Advancement in Soil Behavior, in Situ Test Methods, Pile Foundations, and Tunneling: Selected Papers from the 2009 GeoHunan International Conference, pp. 7-13

[6] Basha, E.A., Hashim, R., Mahmud, H.B. and Muntohar, A.S., (2005), Stabilization of residual soil with rice husk ash and cement. Construction and Building Materials, 19(6), pp.448-453.

[7] Roy, A., (2014). Soil stabilization using rice husk ash and cement. International Journal of Civil Engineering Research, 5(1), pp.49-54.

[8] Edil, T.B., Acosta, H.A. and Benson, C.H., (2006), Stabilizing soft fine-grained soils with fly ash. Journal of Materials in Civil Engineering, 18(2), pp.283-294.

[9] Zumrawi, M.M., (2015), Stabilization of Pavement Subgrade by Using Fly Ash Activated by Cement. American Journal of Civil Engineering and Architecture, 3(6), pp.218-224.

[10] Lingwanda, M. I and Mnkeni, J. K., (2017), Improving Properties of Black Cotton Soil with Quarry Dust. International Journal of Scientific and Technical Research in Engineering, 2(11), pp. 9-15.

[11] Ministry of Works Tanzania (MoW), (2000), Laboratory testing manual, Novum Grafik As, Skjetten, Norway

[12] Singh, P. K., and Sadhwani, K., (2016), Evaluation of Strength Characteristics of Black Cotton Soil Stabilized Using Waste Glass. International Journal of Civil and Structural Engineering Research ISSN 2348-7607, 4(1), pp. 81-86

[13] Naeini, S.A. and Moayed, R.Z., (2009), Effect of plasticity index and reinforcement on the CBR value of soft clay. International Journal of Civil Engineering, 7(2), pp.124-130.

[14] Jyotshna, B., and Chakravarthi, V.K., (2013), Improvement in CBR Performance of High Plastic Soft Subgrade by Placing Stiffer Aggregate Overlying Layer - A Lab Study. International Journal of Engineering Research \& Technology, 2(12), pp. $3261-3265$

[15] Patel, R.S. and Desai, M.D., (2010), CBR predicted by index properties for alluvial soils of South Gujarat. In Proceedings of the Indian Geotechnical conference, Mumbai (pp. 79-82).

[16] Rahim, A.M., (2005), Subgrade soil index properties to estimate resilient modulus for pavement design. International Journal of Pavement Engineering, 6(3), pp.163-169.

\section{BIOGRAPHY}

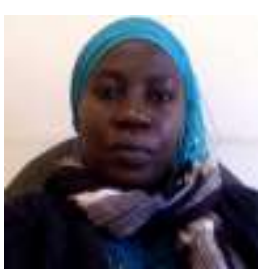

The author holds a PhD in Geotechnical Engineering. She is passionate in teaching and research. This work is part of her efforts to prepare graduates with writing skills. Her areas of interest include use of waste materials in road construction, pavement engineering, soils and foundations 